\title{
Isolation, Modification and Characterization of Tiger-Nut, Maize, Cassava and Potato Starch
}

\section{${ }^{* 1}$ AZEH, Y; ${ }^{1}$ PAIKO, YB; ${ }^{2}$ ABUBAKAR, AY; ${ }^{3}$ GARBA, B; ${ }^{4}$ AMEH, OAE}

\author{
${ }^{1}$ Department of Chemistry, ${ }^{2}$ Department of Biochemistry, Ibrahim Badamasi Babangida University, P. M. B 11, Lapai, Niger State \\ ${ }^{3}$ Department of Chemical and Geological Sciences, Al-hikmah University, Ilorin, Nigeria \\ ${ }^{4}$ Department of Pure and Industrial Chemistry, Kogi State University, Anyigba, Nigeria \\ *Corresponding Author Email: yakubuazeh@gmail.com or azehy@ibbu.edu.ng
}

\begin{abstract}
Four different sources of starchy foods were used for the isolation of starch using commercially cheap and readily available chemical-hypo (3.5\% active Chlorine). The isolated starch was modified through $\mathrm{NaIO}_{4}$ oxidation under mild reaction conditions. Carbonyl functional group test was employed for confirmation of the success of oxidation. FT-IR and Scanning Electron Microscopy (SEM) were used for functional group identification and morphological examination of both modified and native samples to further confirm the success of modification. The appearance of the carbonyl band at $1747-1746 \mathrm{~cm}^{-1}$ and $1647-1637 \mathrm{~cm}^{-1}$ indicated the successful synthesis of oxidized starch. Proximate results showed that the isolated starches were rich in mineral content: $0.25-2.13$; crude fibre: $0.85-3.31$; fat: $0.23-0.28$ and energy: 1331-1410. The study showed that commercial hypo could be a useful replacement for metabisulphite for starch isolation without side effects on starch properties. SEM images showed that morphological architecture of granules was not destroyed during surface functionalization. Characteristic and nutritional features of the oxidized starch showed that it could find useful applications in food and pharmaceutical industries.
\end{abstract}

\section{DOI: https://dx.doi.org/10.4314/jasem.v22i5.21}

Copyright: Copyright (C) 2018 Azeh et al. This is an open access article distributed under the Creative Commons Attribution License (CCL), which permits unrestricted use, distribution, and reproduction in any medium, provided the original work is properly cited.

Dates: Received: 03 March 2018; Revised: 13 April 2018; Accepted: 21 March 2018

Keywords: Tiger-nut, Maize, Cassava, Potato, Modification

Starch is a major carbohydrate storage product found in all chlorophyll-containing plants. It is formed in the presence of sunlight, $\mathrm{CO}_{2}$ and $\mathrm{H}_{2} \mathrm{O}$ (Azeh et al., 2014). It is a white, tasteless and odorless powder insoluble in cold water or alcohol. It is one of the most important flexible food ingredients valuable for useful industrial applications. Major sources are leaves, stems, tubres, seeds and roots of higher plants. Chemically, starch is a carbohydrate polymer consisting of anhydroglucose units linked by $\alpha 1 \rightarrow 4$-glycosidic linkages. Research has shown that it contains 20-25\% amylose and 75-80 $\%$ amylopectin by weight (Brown and Poon, 2005). It is a biodegradable plastic material useful for the production of disposable items (Sun et al., 2002). It is heavily used in food, textiles, cosmetics, plastics, adhesives, paper, and pharmaceuticals industries (Moorthy, 1996; Rowe, 2003). Common sources of food starch are corn, potato, wheat, cassava/tapioca, rice and maize are the most available and accessible sources of starch, but varieties of rice, including waxy rice, pea, sago, oat, barley, rye, amaranth and certain other source of starch indigenous to the areas in which they are produced can be used as localized commercial sources. Maize starch make-up about $80 \%$ of the world market mostly produced in the US (Amani and Hopponen, 1996). Cassava is second to sweet potato as the most important starchy root crop of the tropics (Grace, 1977). The advantages of cassava and potato for starch production over other grains or root crops includes: high purity, excellent thickening characteristics, neutral taste, desirable textural characteristics, relatively cheap with high starch content. Cassava and potato starch have many remarkable characteristics, including high paste viscosity, paste clarity and high freeze-thaw stability which are desirable for many industries. They are renewable, almost unlimited resources and one of the most abundant substances in nature. They are now grown widely as food crops and for industrial purposes. The properties required for a particular application, availability of the starch and economics play a role in selecting a particular native starch for subsequent chemical and/or physical modification.

In Nigeria, cassava and potato are staple foods for both rural and urban areas, which have been transformed from being subsistent crops to industrial cash crops. The use of starch now extends far beyond its original design as a source of energy. Practically, every industry in existence uses starch or its derivatives in one form or another. In food and pharmaceutical industries, starch is used to influence or control such 
characteristics as texture, moisture, consistency and shelf stability. It can be used to bind/disintegrate; to expand/densify; to clarify/opacify; to attract moisture/inhibit moisture; to produce smooth texture/pulpy texture, soft coatings or crisp coatings. It can also be used to stabilize emulsions or to form oil resistant films. It serves as a multifunctional ingredient in the food industry (Cock, 1982; Miyazaki et al., 2006). As a functional carbohydrate, it may be modified physically, chemically or enzymatically to meet specific needs. Starch has been isolated from different sources, modified using different reagents for the production of valuable starch-based products useful for industrial applications.

The objective of the study was to isolate starch using commercial hypo (3.5\% active chlorine) as a replacement for the sodium metabisulphite solution, modify the isolated starch and study the morphological and functional changes.

\section{MATERIALS AND METHOD}

Reagents and Solvents: The tiger-nut, maize, cassava and potato used were obtained in Lapai market, Niger State in Nigeria. All reagents used were of analytical grade. These include; ethanol, methanol, acetone, sodium chloride, sodium hydroxide, sodium periodate and Tolen's reagent. Distilled commercial vinegar was used for acetylation of samples while commercial hypo $(3.5 \% \mathrm{NaOCl})$ and sodium sulphate was used for starch extraction/isolation respectively.

Removal of Gums/Waxy Substances: Tiger-nut, maize powder, cassava and potato tubres cut to sizable pieces were soaked in solution of sodium hypochlorite $(3.5 \%$ $\mathrm{NaOCl}$ ) separately and allowed to stand for $3 \mathrm{~h}$ to remove gums/waxes and discoloration of samples. Afterwards, it was washed and extensively rinsed with distilled water (Azeh et al., 2014).

Starch Isolation from Samples: Pre-treated starch samples were each blended with a blender equipped with razor blades with the addition of solution of hypo at interval of 1 minute during blending to obtain slurries which were filtered using a double two-fold muslin cloth. The filtrate was washed extensively with cold tap water to separate the starch granules. The filtrate was allowed to stand to settle and was decanted after $24 \mathrm{~h}$. Mucilage on the starch was continuously scraped until a pure white starch was obtained. Starch milk obtained was re-suspended in hypo solution for 1 $\mathrm{h}$ for further bleaching. Afterwards, it was washed with distilled water until odour-free of hypo, filtered and air dried over night at room temperature to obtained white starch cake (Azeh et al., 2014; Kenneth et al., 2014).
Mercerization: $5 \mathrm{~g}$ each of oven dried isolated starch was mercerized using $20 \mathrm{~cm}^{3}$ of $17 \%$ sodium hydroxide in a beaker. The mixture was placed on a mechanical shaker and shake for $1 \mathrm{~h}$ (at $75 \mathrm{rmp}$ ). A very thick and colorless gel was obtained for tiger-nut starch samples while a pale-yellow solution was obtained for maize starch sample (Azeh et al., 2014).

Preparation of Dialdehyde Starch: $9.5 \mathrm{~g}$ of sodium periodate (5.0 molar) was dissolved completely in 100 $\mathrm{cm}^{3}$ of distilled water at room temperature followed by the addition of $40 \mathrm{~cm}^{3}$ of prepared sodium periodate solution and $15 \mathrm{~g}$ of starch was added and stirred on a mechanically for $30 \mathrm{~min}$ with the $\mathrm{pH}$ adjusted to 7.0 and left overnight. The reaction temperature was raised to $55^{\circ} \mathrm{C}$. To confirm the success of the reaction, starch slurries obtained were subjected to Tollen's test where a silver mirror deposit on the wall of a test tube was an indication of the presence of aldehyde carbonyl functional group. It was then filtered and the product washed with warm distilled water continuously, until a $\mathrm{pH}$ of 7.0 was attained using a $\mathrm{pH}$ indicator paper. The slurry was filtered and dried for $24 \mathrm{~h}$ at $50^{\circ} \mathrm{C}$ in an oven (Salisu et al., 2013).

Proximate Analysis of Starch Samples: The proximate analysis of starch samples were carried out at National Cereals Research Institute, Badeggi, Bida, Niger state, Nigeria.

Scanning Electron Microscopy and Infrared Spectroscopy: Scanning electron microscopy and Infrared Spectroscopy of modified starch and control samples were done Ahmadu Bello University, Zaria, Nigeria.

\section{RESULTS AND DISCUSSION}

Proximate Analysis of Starch Samples: The proximate analysis (\%) of the modified/native starch samples was determined. The moisture content of the extracted starch were closely related and falls in the range 8.85$11.54 \%$ Table 1 . The order of increase in the amount of moisture was Potato $>$ Cassava $>$ Tiger-Nut $>$ Maize starch. The amount of moisture in a food sample is important because it provides information on the storage shelf-life of a food. Potato starch had high moisture content than the others studied, which explains the inability of potato to resist microbial attack. Hence, it easily deteriorates when kept for a long period of time. The maximum allowable limit for moisture in starch flour is $14 \%$ (Austin, 1984). The present results showed that all samples exhibited moisture content (\%) within the maximum allowable limit. Cassava starch had the lowest crude protein $(0.47 \%)$ and fibre $(0.82 \%)$. The energy values of the 
extracted starches showed close similarities with the exception of maize starch Table 1. Cassava starch had the highest ash content which was indicative of the amount of non-volatile inorganic matter in the sample. Carbohydrate contents obtained by difference for maize, cassava and potato starch were similar while tiger nut starch was an exception with its very low value $(38.19 \%)$ of carbohydrate. Proximate analysis (\%) of tiger nut starch in the present study had closely related values in terms of ash- 0.27 and moisture-9.36 while deviations were observed for fat- 0.23 ; protein2.65 and $\mathrm{CHO}-38.19$ compared to the results obtained by (Kenneth et al., 2014). The observed deviations may be due to differences in the method and / or sources of the sample used. The ash content (\%), cassava-2.13, was the highest, which implied that it had more of the non-volatile inorganic compounds than all other samples studied Table 1. The low ash content was an indication of clean processing (Alejandro et al., 2008). In the isolated starch, the major component was carbohydrate, with high energy values obtained for all samples. All other proximate factors such as fat, protein, minerals and moisture were in minor amounts and varies from one starchy crop to the other (Taik et al., 1999; Gonzalez et al., 2002; Miyazaki et al., 2006; Nandan et al., 2006; Olawale et al., 2007; Klanarong, 2009; Sangeethong et al., 2010; Singh et al., 2011; Azeh et al., 2014; Kenneth et al., 2014).

Table 1. Proximate Composition of Isolated Tiger nut, Maize, Cassava and Potato Starch

\begin{tabular}{llllllllll}
\hline S/NO & Sample & $\begin{array}{l}\text { Moisture } \\
(\boldsymbol{\%})\end{array}$ & $\begin{array}{l}\text { Protein } \\
(\boldsymbol{\%})\end{array}$ & $\begin{array}{l}\text { Fat } \\
(\boldsymbol{\%})\end{array}$ & $\begin{array}{l}\text { Crude fiber } \\
(\boldsymbol{\%})\end{array}$ & $\begin{array}{l}\text { Ash } \\
(\boldsymbol{\%})\end{array}$ & $\begin{array}{l}* \mathbf{C H O} \\
(\boldsymbol{\%})\end{array}$ & $\begin{array}{l}\text { Energy } \\
(\mathbf{K j})\end{array}$ & $\begin{array}{l}\text { Value } \\
(\mathbf{K c a l})\end{array}$ \\
\hline 1 & Tiger-Nut & 9.36 & 2.65 & 0.23 & 3.31 & 0.27 & 38.19 & 343.03 & 1372.12 \\
& Starch & & & & & & & & \\
2 & Maize Starch & 8.85 & 2.77 & 0.25 & 2.05 & 0.25 & 84.83 & 352.65 & 1410.60 \\
3 & Cassava Starch & 10.48 & 1.73 & 0.39 & 2.47 & 2.13 & 81.69 & 332.97 & 1331.88 \\
4 & Potato Starch & 11.54 & 0.47 & 0.28 & 0.85 & 0.26 & 82.54 & 337.66 & 1350.64 \\
\hline
\end{tabular}

*CHO was obtained by difference and energy values were by calculation. Minerals measured in mg/100 $g$.

S. Morphological Properties of Modified and Unmodified Starch Samples: Scanning Electron Micrographs of native and oxidized starch are shown in Figure 1. Native tiger-nut, maize, cassava and potato starch granules exhibited various morphologies ranging from spherical, round, grooved, and irregular polygonal shapes with truncated ends (Rutenberg and Solarek, 1984).
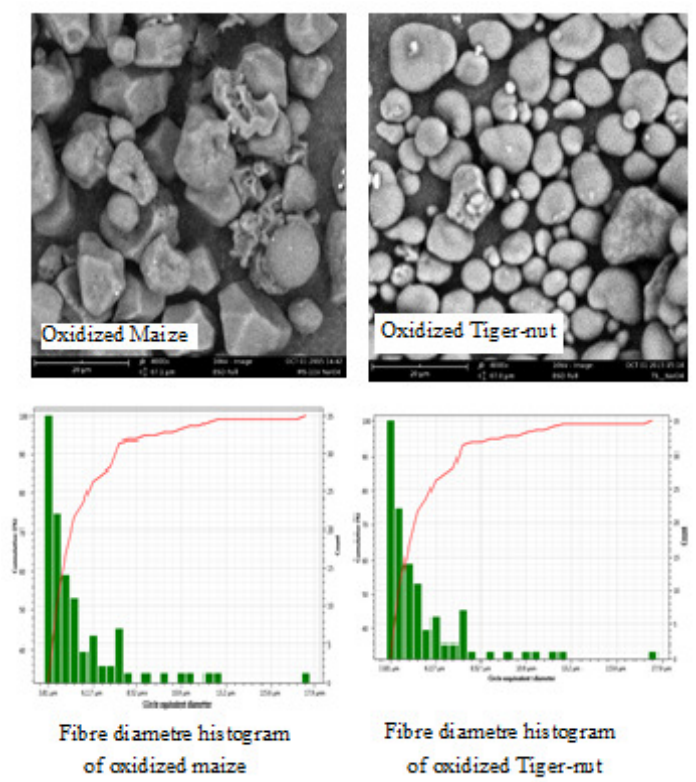

Fig. 1. Morphology of Oxidized Starch Granules and Granule Diameter of Maize and Tiger -Nut
There were some visual changes on the external surface of modified samples such as maize, cassava and potato starches which have been attributed to chemical treatments. Modified tiger-nut starch had smoother surface after chemical treatment and this implied that periodate oxidation did not damage the granule`s surface. Treated samples exhibited different granular morphologies and had smaller sized particles compared to untreated samples. The differences in the granular architecture and fragility of starch granules were due to differences in botanical sources (Rotenberg and Solarek, 1984).

Surface erosion as revealed by SEM images showed that tiger-nut starch granules were more rigid and resistant to chemical attack than the others. The significance of such granular size and surface is that, they could easily be dispersed in aqueous medium with good stabilizing effect.

According to Rutenberg \& Solarek (1984), periodate oxidation up to $6 \%$ active ingredient left corn and rice starch surfaces unaffected. Kuakpetoon and Wang (2001), observed no changes on granule morphology of corn and rice starches modified with sodium periodate at the levels of 0.8 and $2 \%$ active ingredient.

Similar observations were evidenced in the present study by SEM images of both treated and native starch samples. The changes observed are probably due to differences in the isolation methods. 

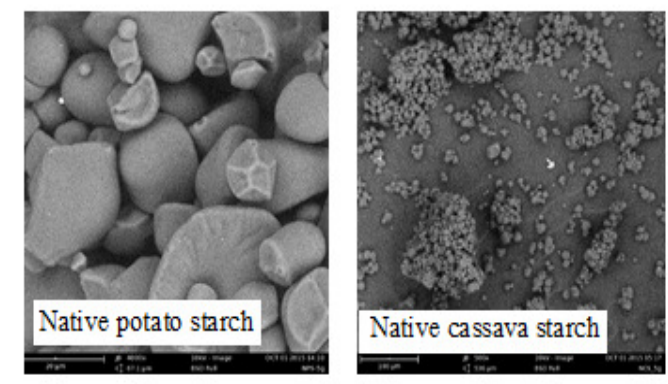

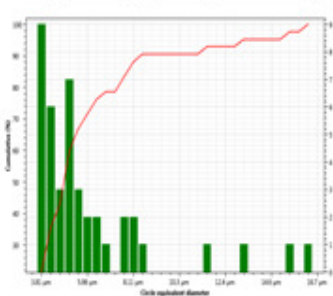

Fibre diametre histogram of native potato

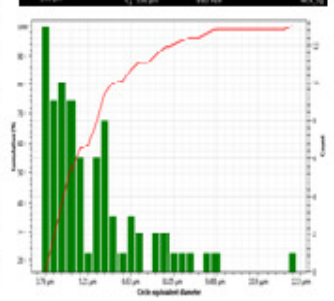

Fibre diametre histogram of native cassava
Fig. 2. Morphology of Oxidized Starch Granules and Granule Diameter of Potato and Cassava Starch

Starch granule diameter and frequency distribution shown by histogram (Figure 2) revealed granule diameters in the range 3.81 to $6.18 \mu \mathrm{m}$ for both oxidized tiger-nut and maize starch. The implication for the small sized particles is that, they would form good candidates for industrial and pharmaceutical applications due to their large surface area (Kong et al., 2009).

FT-IR Study: This study revealed the formation of certain important functional groups due to oxidation of the $-\mathrm{OH}$ groups in starch molecules. The following important functionalities were revealed: The band at $3918-3360 \mathrm{~cm}^{-1}$ was due to bonded -OH groups in starch (Salisu et al., 2013; Azeh et al., 2016). The band at $1747-1746 \mathrm{~cm}^{-1}$ in tiger nut starch was due to carbonyl $(\mathrm{C}=\mathrm{O})$ stretch, which confirmed the formation of oxidized starch. Other important absorption bands which confirmed the formation of carboxyl groups attributable to further oxidation of the carbonyl groups were observed around 1647 - 1637 $\mathrm{cm}^{-1}$ (Azeh et al., 2016). The presence of pectins and lignin were indicated by the appearance of the bands around 1559-1508 $\mathrm{cm}^{-1}$ and $1458-1420 \mathrm{~cm}^{-1}$ (Sunan et al., 2011). The band at $1375-1339 \mathrm{~cm}^{-1}$ has been attributed to $-\mathrm{CH}_{2}$ bending deformation vibrations in starch. Band peaks at $1243-1239 \mathrm{~cm}^{-1}$ are assigned to vibrations of the methyl ester groups in starch. The peaks at $1144-850 \mathrm{~cm}^{-1}$ are characteristic absorptions of $\mathrm{C}-\mathrm{O}$ stretch in $\mathrm{C}-\mathrm{O}-\mathrm{C}$ and $\mathrm{C}-\mathrm{O}-\mathrm{H}$ of the glycosidic links in starch (Azeh et al., 2016).
Conclusion: In conclusion, this study demonstrates that commercial hypo could be useful in the isolation of industrial/pharmaceutical grade starch. Proximate results of the starches isolated were within the range obtained with other standard methods. Granule morphology was intact as well as surface functionalities as revealed by SEM and FT-IR, which implied that the polymer structure was not destroyed. Hypo could be useful as a replacement for metabisulphite to prevent starch browning and for the isolation of anionic starch. Starch modification was successful as revealed by FT-IR results.

Acknowledgments: The authors acknowledged the technical staff of the Department of Chemistry IBBU Lapai for the technical assistance provided during this research.

\section{REFERENCES}

Austin, GT (1984). Shreve's Chemical Process Industries, Fifth Edition, McGraw-Hill Book Company, pp 567.

Amani, NR; Hopponen, RE (1996). Through swelling behavior and pasting properties of cross-linked waxy maize starches. Starch, 389 - 397

Alejandro, A; Felipe, G; Francisco, J; Juscelino, T; Luis, AB (2008). Physicochemical and functional properties of cross-linked banana resistant starch: Effect of pressure cooking. Starch, 60 (6): 286 291.

Azeh, Y; Abubakar, RM; Umar, MT (2014). Isolation and acetylation of starch using ethanoic acid for industrial uses. Ilorin J. of Sci. 1 (2): 301 - 318.

Azeh, Y; Paiko, YB; Elele, UU; Adesina, GO; Mohammad, MA; Mohammed, DZ; Gimba, AA (2016). Isolation of cassava starch and synthesis of acetyl derivatives using vinegar. Lapai j. Appl. Nat. Sci. 1 (1): 89 - 103.

Brown, WH; Poon, T (2005). Introduction to organic chemistry (3rd ed.), Wiley.

Cock, JH (1982). Cassava: A basic energy source in the tropics. Sci. 218 (4574): $755-762$.

Grace, MR (1977). Cassava Processing, FAO Plant Production and Protection Series No. 3, 2.

Gonzalez, Z; Perez, E (2002). Effect of acetylation on some properties of rice starch. Starch/Starke, 54: $148-154$. 
Klanarong, A (2009). Biodegradable plastics from cassava starch in Thailand.

Kuakpetoon, D; Wang, YJ (2001). Characterization of different starches oxidized by sodium periodate. Starch/Starke, 53: 211-218.

Kenneth, AK; Afolayan, MO; Oberafo, AA; Thomas, $S$ (2014). Isolation and physicochemical characterization of tigernut (Cyperus esculentus) starch as a potential industrial biomaterial. Int. J. Mat. Sci. and Appl. 3 (2): 37 - 41.

Morthy, SN (1996). Starch and starch derivatives in food. Trends Carbohy. Chem. 425:

$133-139$.

Miyazaki, MR; Hung, PV; Maeda, T; Morita, N (2006). Recent advances in application of modified starches for bread making. Trends in Food Sci. Technol. 17: 591 - 599.

Nandan, S; Umashankar, A; Shankar, CD (2011). Effect of cellulose treatment on extraction of starch from potato. Int. Food Res. J. 18: 337-346.

Olawole, JO; Oluwatoyin, FO (2007). Development of a sustainable system for Cassava Starch Extraction. Tropentag 2007 University of KasselWitzenhausen and University of Gottingen. Conference on Int. Agri. Res. for Dev. 1-4. October 9 - 11 .

Rutenberg, MW; Solarek, D (1984). Starch derivatives: production and uses in Starch: Chemistry and Technology, Academic Press, London, p. 311.
Rowe, CR; Sheskey, P j; Weller, Pj (2003). Effects of ph on the physicochemical and binder properties of tiger nut starch. Starch/starke, 55 (454): 311 388.

Sun, XS; Radosavljevic, M; Seib, PA (2002). Center for crops utilization research, Iowa agriculture \& home economics experiment station, Cereal Chem., Team. Ames, IA: Iowa State University.

Sangseethong, KT; Sriroth, K (2010). Characterization of physico-chemical properties of hypochlorite and peroxide-oxidized cassava starches. Carb. Poly. 82: 446 - 453.

Singh, L; Sharma, V; Sharma, S (2011). Preparation and characterization of modified starch isolation from amaranthus linn. Int. J. Curr. Phar. Res. 3: 62-64.

Sunan, J; Thawien, W; Waranyou, S (2011). Improvement of poly (vinyl alcohol) adhesives with cellulose microfibre from sugarcane bagasse. Iranian Poly. J. 20 (4): 305 - 317.

Salisu, AA; Musa, H; Abba, H; Kogo, AA (2013). Preparation and characterization of dialdehyde starch and its` cross-linking with copper (II) ion. J. Chem. Phar. Res. 5 (5): 153 - 158.

Taik, L; Lee, J; Hoonshin, D; Lim, HS (1999). Comparison of protein extracted solutions for rice starch isolation and effects of residual protein content on starch pasting properties. Starch, 51: $120-125$. 